\title{
Rectal artemisinins for malaria: a review of efficacy and safety from individual patient data in clinical studies Melba Gomes*1, Isabela Ribeiro ${ }^{1,7}$, Marian Warsame ${ }^{2,3,6}$, Harin Karunajeewa ${ }^{4}$ and Max Petzold ${ }^{2,5}$
}

\begin{abstract}
Address: ${ }^{1}$ UNICEF/UNDP/World Bank/WHO Special Programme for Research and Training in Tropical Diseases, World Health Organization, 20 Avenue Appia, Geneva 27, Switzerland, 2Division of International Health (IHCAR), Karolinska Institutet, Stockholm, Sweden, ${ }^{3}$ Rectal Artesunate Study Team, National Institute for Medical Research (NIMR), Dar es Salaam, Tanzania, ${ }^{4}$ University of Western Australia, Crawley, Western Australia and Papua New Guinea Institute of Medical Research, Goroka EHP 441, Papua New Guinea, ${ }^{5}$ Nordic School of Public Health, Göteborg, Sweden, ${ }^{6}$ Global Malaria Programme, World Health Organization, 20 Avenue Appia, Geneva 27, Switzerland and ${ }^{7}$ Drugs for Neglected Diseases - DNDi, Regional Office - Latin America, Rua Santa Luzia 651/11 ${ }^{\circ}$ andar, 20030-041 - Rio de Janeiro, Brasil
\end{abstract}

Email: Melba Gomes* - gomesm@who.int; Isabela Ribeiro - iribeiro@dndi.org; Marian Warsame - warsamem@who.int; Harin Karunajeewa - harin@cyllene.uwa.edu.au; Max Petzold - max@nhv.se

* Corresponding author

Published: 28 March 2008

BMC Infectious Diseases 2008, 8:39 doi:10.1 186/147/-2334-8-39
Received: 6 July 2007

Accepted: 28 March 2008

This article is available from: http://www.biomedcentral.com/I47/-2334/8/39

(C) 2008 Gomes et al; licensee BioMed Central Ltd.

This is an Open Access article distributed under the terms of the Creative Commons Attribution License (http://creativecommons.org/licenses/by/2.0), which permits unrestricted use, distribution, and reproduction in any medium, provided the original work is properly cited.

\begin{abstract}
Background: Rectal administration of artemisinin derivatives has potential for early treatment for severe malaria in remote settings where injectable antimalarial therapy may not be feasible. Preparations available include artesunate, artemisinin, artemether and dihydroartemisinin. However each may have different pharmacokinetic properties and more information is needed to determine optimal dose and comparative efficacy with each another and with conventional parenteral treatments for severe malaria.
\end{abstract}

Methods: Individual patient data from 1167 patients in 15 clinical trials of rectal artemisinin derivative therapy (artesunate, artemisinin and artemether) were pooled in order to compare the rapidity of clearance of Plasmodium falciparum parasitaemia and the incidence of reported adverse events with each treatment. Data from patients who received comparator treatment (parenteral artemisinin derivative or quinine) were also included. Primary endpoints included percentage reductions in parasitaemia at 12 and 24 hours. A parasite reduction of $>90 \%$ at 24 hours was defined as parasitological success.

Results: Artemisinin and artesunate treatment cleared parasites more rapidly than parenteral quinine during the first 24 hours of treatment. A single higher dose of rectal artesunate treatment was five times more likely to achieve $>90 \%$ parasite reductions at 24 hours than were multiple lower doses of rectal artesunate, or a single lower dose administration of rectal artemether.

Conclusion: Artemisinin and artesunate suppositories rapidly eliminate parasites and appear to be safe. There are less data on artemether and dihydroartemisinin suppositories. The more rapid parasite clearance of single high-dose regimens suggests that achieving immediate high drug concentrations may be the optimal strategy. 


\section{Background}

In 1985, the Journal of Traditional Chinese Medicine described the satisfactory efficacy of qinghaosu suppositories in 100 patients with $P$. falciparum malaria, 4 of whom had cerebral malaria [1]. Qinghaosu (artemisinin) derivatives were soon recognised as having powerful antimalarial activity [2] and a variety of formulations have since been developed[3]. The efficacy and safety of oral and parenteral artemisinin derivatives have been widely studied for both uncomplicated and severe malaria [4-7] and these drugs form the basis of current antimalarial treatment policy in most countries in the world [8].

During the past 10 years, the WHO has directed the development of the highly active artemisinin derivative, artesunate, to assess its value in settings where it might be given rectally as a substitute for injectable treatment. The rationale for the development was that, without effective treatment, $P$. falciparum malaria can progress to severe malaria and death within a matter of hours. The artemisinin derivatives have been shown to have potent activity against early trophozoite forms and to rapidly reduce heavy parasite infections[3]. Therefore it was postulated that when given as a suppository in areas where patients cannot immediately access injectable therapy, they might confer therapeutic advantages in preventing parasite development to the more pathological stages that cause organ complications in severe malaria [9]. Rectal preparations have the advantage of being easy to administer in rural areas; therefore it is anticipated that rectal administration of an artemisinin derivative in remote settings might "buy time" by halting or slowing the progress of disease while a patient is being transported to a health-care facility equipped to provide definitive treatment. Their utility would consequently be greatest in areas where access to injectable therapy is poor or does not exist. The clinical evidence accumulated in the initial phase of this development focused on measures of parasite reduction - a wellestablished indicator of clinical effect in the evaluation of antimalarial drugs.

In addition to artesunate, other artemisinin derivatives formulated for rectal administration now include artemisinin, dihydroartemisinin and artemether. The available published results suggest that all achieve a rapid, consistent clinical response in regions where studies have been undertaken, despite considerable inter-individual pharmacokinetic variability[10-14]. However the different artemisinin derivatives have different physicochemical properties in adminstration; consequently some preparations might be more rapidly absorbed than others $[11,13,15-18]$. Most clinical trials have employed small sample sizes and none have directly compared the efficacy of the different rectally administered artemisinin derivatives with one another. In addition, substantial heteroge- neity exists with respect to the dosing schedules employed. There is therefore considerable uncertainty regarding the optimal preparation and dosing schedules to use.

Given the different aims, design, location, patient demographics and disease severity of clinical trials, we review individual patient data from several trials to establish whether there are significant differences in efficacy and safety of different artemisinin-based suppositories in the first 24 hours post treatment. More specifically we evaluate: i) the efficacy of rectal artemisinins in comparison with conventional treatments for severe malaria (including parenteral quinine and parenteral artemisinins); ii) the comparative efficacy of different artemisinin derivatives for rectal use (namely, artesunate vs artemisinin vs artemether); iii) the efficacy of different dosing regimens (single vs multiple dosing) and total dose administered; iv) the overall safety profile of rectally administered artemisinins and differences between different drugs and regimens.

\section{Methods}

\section{Search strategy and selection criteria}

Electronic searches of the National Library of Medicine's MEDLINE database, Current Contents database and manual searches of selected specialty journals were performed to identify all the pertinent literature. MEDLINE database engines (Ovid, PubMed and GratefulMed) were used with the keywords "rectal", "artemisinin", and "treatment". The search was further refined with the words "artesunate", "artemether", "artemisinin", "dihydroartemisinin", "suppositories", and "rectocaps" from 1980 to March 2006. Reference lists from qualitative topic reviews and published clinical trials in English were also searched. We attempted to obtain the original individual patient data from all studies, regardless of publication status.

Selection criteria for inclusion of studies were clinical trials that assessed the efficacy of a rectal artemisinin-based preparation where individual patient data (inclusion/ exclusion criteria, age, parasitological status at baseline and parasitology post treatment) were available. Comparative and non-comparative studies were included, regardless of study design, geographical area, patient age group, disease severity or the artemisinin derivative used. Safety data and information on dosage was specifically requested from the individual study investigators if this was not provided or evident from a publication. Data extraction was conducted by two investigators (MP, IR) for efficacy data and two investigators (MW, MG) for safety. 


\section{Efficacy endpoints}

The main focus of the review was on the assessment of parasite reduction and clinical response of patients during the first 24 hours following treatment. This was considered most appropriate, given the intended indication as emergency pre-referral treatment, where ameliorating disease progression within 24 hours, i.e. while the patient is being transported to a clinic or hospital, is likely to be most important.

All efficacy definitions used are consistent with the scientific literature. Parasite reduction ratio (PRR) at 12 and 24 hours was assessed as the percent reduction of parasitaemia at 12 and 24 hours from baseline parasitaemia. Parasitological success was defined as the absence of clinical deterioration from baseline and a PRR at 24 hours of $\geq$ $90 \%$. In the analysis (see further below) both the continuous variable PRR and the binary variable of $\geq 90 \%$ parasite reduction were used, the former to define efficacy at 12 hours, and the latter to define efficacy at 24 hours.

Because definitions of parasite and fever clearance times differed from study to study, these time-to-event variables were re-derived from the serial parasite density estimations and temperatures for individual patients. Parasite clearance and fever clearance time were defined as the time at which the first negative blood smear or normal temperature $\left(<37.5^{\circ} \mathrm{C}\right.$ axillary or $<38.0^{\circ} \mathrm{C}$ oral) was recorded. The effect of consolidation treatment on recrudescence of the infection during follow-up was evaluated from baseline to the reappearance of parasitaemia.

\section{Safety endpoints}

Except in two trials, laboratory markers of safety (including haematological and biochemical indices) were not available. Safety analyses were consequently restricted to clinical descriptions of reported adverse events. In the absence of prospective standardised methods for defining, assessing, reporting and classifying adverse events across all trials, and due to inherent difficulties in clinically distinguishing drug side-effects from manifestations of malarial infection, principal investigators who contributed data were asked to re-review individual patient data retrospectively and reassess all reported adverse events. Ideally this was performed directly from case record forms where archived data were accessible. Each reported event was thus re-classified by the clinical investigator as being either "unlikely", "possibly", "probably" or "definitely" due to the treatment. Those events considered possibly, probably or definitely drug-related were thereafter re-classified as "potentially drug-related" for the purposes of the pooled analysis.

\section{Statistical analysis}

Original data from different studies were merged into a master data set. In the analysis mainly hierarchical models were used, with treatment arm as the second level of clustering. In some cases within-study comparisons of different treatment arms was possible and methods for metaanalysis were then accordingly applied in the analysis of PRR. A hierarchical mixed model applying the DerSimonian \& Laird method was used with the estimate of heterogeneity being taken from the inverse variance fixed-effect model [19].

Most of the analyses, however, were based on comparisons of treatment arms from different studies, here called pooled analyses, and conducted as follows: For PRR, linear mixed effect models with random intercepts were applied. In the analysis at 12 hours, an identity link (normal distribution) was used. At 24 hours a large proportion of the PRR values for the artemisinins were close to $100 \%$ at 24 hours, and these were then categorised into binary observations ( PRR $>90 \%$ versus $<90 \%$ ). A logistic link was then used in the analysis. It should be noted that crude mean values of PRR at 24 hours using the identity link are also given for description. We systematically examined the effect (stepwise backward elimination of covariates not reaching a significance level of $\mathrm{p}=0.05$ ) of the following covariates within all analyses: baseline parasitaemia, age, region, total treatment dose provided within the initial 12 and 24 hours, and severity of disease as defined by the evaluating clinician.

Time-to-event analyses, including time to parasite and fever clearance and the efficacy of the consolidated treatment in suppressing parasitaemia post treatment (reappearance of parasites), were represented using crude Kaplan-Meier plots (these are provided as graphs only where the difference in estimates was significant). Hazardratios were estimated using a non-hierarchical Cox regression model applying the same stepwise backward elimination of covariates as above. Intra-rectal treatments were compared to parenteral treatment when followed by the same consolidation treatment in one analysis and intrarectal treatments followed by different consolidation treatments were compared in a second analysis. Time to parasite clearance, age, region, disease severity, parasitaemia at 72 hours (often the start of consolidation treatment) were assessed as covariates through stepwise backward elimination of covariates.

All statistical computations were performed with Stata for Windows (version 8 and 9.2, Stata Corporation, College Station, Texas-USA). 


\section{Results}

\section{Studies included}

A total of 27 studies were identified in patients using the search criteria; 4 studies were in healthy normal volunteers $[11,15,16,18]$. Twelve studies were not included in the analysis: 5 trials were on pharmacokinetics -8 to 15 patients per trial, total of 59 patients $[14,17,20-22]$ with no efficacy data available. This left 7 trials, 242 patients with uncomplicated malaria[23-26] and 185 patients with severe and complicated malaria treated with rectal artemisinins $[23,27-29]$ that were not available to be included in our analyses.

Individual patient data were available from 15 clinical trials (Table 1). There were 4 randomised, controlled, clinical trials with parenteral quinine as comparator: Molyneux1997-8 [30], Barnes1998 [30], Phuong1992-5 [31], Aceng2002-3 [32], and 6 trials in which the comparator was another artemisinin given parenterally or orally in moderately severe, hyperparasitaemic and severe patients: Krishna1996 [10], Looareesuwan1996 (unpublished), VanVugt1997-9 (unpublished), Vinh 1997-9 [33], Hien1998 (unpublished), Karunajeewa2003-4 [34]. The remaining trials used a different dosage or treatment regimen with the same artemisinin-based rectal preparation as a comparator: Looareesuwan1995 [35], Looareesuwan2000 (unpublished), Than1998 (unpublished). There were 2 non- comparative trials Bhatt1994-5 [36], Karunajeewa2001 [37]. We were provided with an additional 10 individual patient observations not included in one published trial (Phuong19925) [31] which completed with fewer patients than planned due to recruitment difficulties, but where the team continued to collect clinical descriptions of severe malaria in children, using rectal artemisinins which the hospital preferred to quinine. The data from these 10 cases were added to the pooled analyses.

Altogether the studies included in this analysis enrolled a total of 1167 patients in 37 separate treatment arms. Five patients who simultaneously received rectal artesunate and quinine were excluded, leaving a total of 1162 patients included in the analysis. Of these 786 had been treated with rectal administration of an artemisinin derivative and 376 with a comparator drug which was either a parenteral artemisinin (236) oral artesunate (17) or parenteral quinine (123). The majority of included patients treated with a rectal artemisinin were from mainland South East Asia (487) or Papua New Guinea (89), with relatively fewer patients from Africa (210). Thirtyone percent of patients were children under $5,11.8 \%$ children aged $6-10,21.3 \%$ adolescents aged $11-20$ years and $36 \%$ adults over 20 years of age. Treatment exposure information is provided in Table 2.

\section{Efficacy \\ I comparisons with quinine}

Two studies (Molyneux1997-8 and Barnes1998) contributed to a standard meta analysis as both studies compared clinical and parasitological response of artesunate $10 \mathrm{mg} /$ $\mathrm{kg}$ versus quinine $10 \mathrm{mg} / \mathrm{kg}$. The log-transformed PRR at $24 \mathrm{~h}$ with a single dose of rectal artesunate was significantly better than quinine, weighted mean difference 0.60 (95\% CI 0.32-0.89, p $\leq 0.0001$ ). The pooled analyses showed that the artemisinin derivatives, regardless of route of administration and number of doses, were superior to quinine in reducing parasitaemia at 12 and 24 hours (Figure 1 and Table 3 ). In the model, parasitological efficacy was partly dependent on age and severity of disease but independent of baseline parasitaemia and region of use.

Time to clearance of parasitaemia for the different drugs are given in Figure 1. Multiple Cox regression analysis showed a significant difference in time to clearance between parenteral artemisinins and parenteral quinine (Hazard Ratio HR $=4.1 ; \mathrm{p} \leq 0.0001$ ), between single dose rectal artesunate and parenteral quinine $(\mathrm{HR}=2.7 ; \mathrm{p} \leq$ $0.0001)$ and between single dose artemisinin suppositories and quinine $(\mathrm{HR}=2.4 ; \mathrm{p}=0.03$ ) with parasitaemia at baseline being a significant covariate in the parenteral comparison ( $\mathrm{HR}=0.99 ; \mathrm{p} \leq 0.0001)$ and in the comparison with single dose artesunate $(H R=0.99 ; \mathrm{p}=0.042)$, but not in the comparison with single dose artemisinin suppository treatment.

\section{Comparisons between artemisinin derivatives}

Mixed model estimates comparing efficacy of the different artemisinin derivatives are provided in Table 4.

\section{I Parenteral versus rectal administration}

Parenteral artesunate or artemether versus single-dose artemisinin or artesunate rectal administration

Mean PRR using either a single dose artesunate or single dose artemisinin was higher than parenteral artemisinins at 12 hours $(65.9 \%$ for rectal treatment compared with $60.0 \%$ for parenteral treatment). This was observed also in the adjusted model presented in Table 4, in which severe disease was an important covariate in response prior to 12 hours. At 24 hours the difference was in the same direction, with $90.0 \%$ reduction in parasitaemia with rectal artemisinins compared with $83.8 \%$ parasite reduction with parenteral artemisinins. The proportion $\mathrm{PRR}>90$ at 24 hours gave an $\mathrm{OR}=1.75(\mathrm{p}=0.072)$ in favour of rectal administration. However, the Kaplan Meier survival plot provided in Figure 2 demonstrates the overall superiority of parenteral administration beyond the 24-hour period (unadjusted log rank test of survival function $\mathrm{p} \leq 0.0001$ for a single dose of rectal artesunate/ artemisinin versus parenteral treatment). Baseline parasite 
Table I: Studies for which individual patient data was provided, by study, treatment and number of patients

\begin{tabular}{|c|c|c|c|c|c|c|c|}
\hline \multirow[t]{2}{*}{ Region } & \multirow[t]{2}{*}{ Country } & \multirow{2}{*}{$\begin{array}{c}\text { Study } \\
\text { Identification* } \\
\text { [Ref] }\end{array}$} & \multirow[t]{2}{*}{ Treatment Group } & \multicolumn{3}{|c|}{ Number of Patients Studied } & \multirow{2}{*}{$\begin{array}{c}\text { Total Number of } \\
\text { Patients }\end{array}$} \\
\hline & & & & Moderately Severe & Severe & Uncomplicated & \\
\hline \multirow[t]{10}{*}{ Africa } & Ghana & Krishna $1996[10]$ & $\begin{array}{l}\text { Artesunate ir, single } \\
\text { dose }\end{array}$ & 23 & & & 23 \\
\hline & & & $\begin{array}{c}\text { Artemisinins** } \\
\text { parenteral }\end{array}$ & 11 & & & 11 \\
\hline & Kenya & Bhatt 1994-5 [36] & $\begin{array}{l}\text { Artesunate ir, multiple } \\
\text { dose }\end{array}$ & & 23 & & 23 \\
\hline & Malawi & $\begin{array}{c}\text { Molyneux 1997-8 } \\
{[30]}\end{array}$ & $\begin{array}{c}\text { Artesunate ir, single } \\
\text { dose }\end{array}$ & 86 & & & 86 \\
\hline & & & Quinine parenteral & 22 & & & 22 \\
\hline & South Africa & Barnes $1998[30]$ & $\begin{array}{c}\text { Artesunate ir, single } \\
\text { dose }\end{array}$ & 27 & & & 27 \\
\hline & & & Quinine parenteral & 8 & 6 & & 14 \\
\hline & & & $\begin{array}{l}\text { Quinine parenteral+ } \\
\text { Artesunate ir }\end{array}$ & & 5 & & 5 \\
\hline & Uganda & Aceng 2002-3 [32] & $\begin{array}{c}\text { Artemether ir, single } \\
\text { dose }\end{array}$ & & 51 & & 51 \\
\hline & & & Quinine parenteral & & 52 & & 52 \\
\hline \multicolumn{4}{|c|}{ Total Number of Patients - Africa } & 177 & 137 & & 314 \\
\hline \multirow[t]{17}{*}{ Asia- Oceania } & Myanmar & Than 1998 & $\begin{array}{l}\text { Artesunate ir, multiple } \\
\text { dose }\end{array}$ & & 100 & & 100 \\
\hline & Papua New Guinea & $\begin{array}{c}\text { Karunajeewa 200I } \\
\text { [37] }\end{array}$ & $\begin{array}{l}\text { Artesunate ir, multiple } \\
\text { dose }\end{array}$ & & & 48 & 48 \\
\hline & Papua New Guinea & $\underset{\text { Karunajeewa 2003-4 }}{\text { Kare }}$ & $\begin{array}{l}\text { Artesunate ir, multiple } \\
\text { dose }\end{array}$ & & 41 & & 41 \\
\hline & & & $\begin{array}{c}\text { Artemisinins } \\
\text { parenteral }\end{array}$ & & 38 & & 38 \\
\hline & Thailand & Looareesuwan 1996 & $\begin{array}{c}\text { Artesunate ir, single } \\
\text { dose }\end{array}$ & 26 & & & 26 \\
\hline & & & $\begin{array}{c}\text { Artemisinins } \\
\text { parenteral }\end{array}$ & 24 & & & 24 \\
\hline & Thailand & Van Vugt 1997-9 & $\begin{array}{c}\text { Artesunate ir, single } \\
\text { dose }\end{array}$ & 44 & & & 44 \\
\hline & & & Artesunate po & 17 & & & 17 \\
\hline & Thailand & $\begin{array}{c}\text { Looareesuwan } 1995 \\
{[35]}\end{array}$ & $\begin{array}{l}\text { Artesunate ir, multiple } \\
\text { dose }\end{array}$ & 60 & & & 60 \\
\hline & Thailand & Looareesuwan 2000 & $\begin{array}{c}\text { Artesunate ir, single } \\
\text { dose }\end{array}$ & 69 & & & 69 \\
\hline & Vietnam & Phuong |992-5 [3|] & $\begin{array}{l}\text { Artemisinin, multiple } \\
\text { dose }\end{array}$ & & 46 & & 46 \\
\hline & & & $\begin{array}{l}\text { Artemisinins } \\
\text { parenteral }\end{array}$ & & 40 & & 40 \\
\hline & & & Quinine parenteral & & 35 & & 35 \\
\hline & Vietnam & Vinh 1992-4 [33] & $\begin{array}{l}\text { Artemisinin ir, } \\
\text { multiple dose }\end{array}$ & & 52 & & 52 \\
\hline & & & $\begin{array}{l}\text { Artemisinins } \\
\text { parenteral }\end{array}$ & & 123 & & 123 \\
\hline & Vietnam & Hien 1998 & $\begin{array}{c}\text { Artemisinin ir, single } \\
\text { dose }\end{array}$ & & 46 & & 46 \\
\hline & & & $\begin{array}{c}\text { Artesunate ir, single } \\
\text { dose }\end{array}$ & & 44 & & 44 \\
\hline \multicolumn{3}{|c|}{ Total Number of Patients - Asia } & & 240 & 565 & 48 & 853 \\
\hline Grand Total & & & & 417 & 702 & 48 & 1167 \\
\hline
\end{tabular}

* Study Identification: Investigator name and year of patient enrolment [References are included where available].

** Artemisinins parenteral: this consisted of Artemether or Artesunate administered via intra-muscular or intravenous route 
Table 2: Summary of Age and Doses used in clinical trials by type of therapy $(\mathrm{mg} / \mathrm{kg})$

\begin{tabular}{|c|c|c|c|c|}
\hline Treatment group & Median age, years (range) & $\begin{array}{l}\text { Dose }(\mathrm{mg} / \mathrm{kg}) \text { at Initiation of } \\
\text { therapy }(\text { mean } \pm \text { SD) }\end{array}$ & $\begin{array}{c}\text { Total dose over first I2 } \\
\text { hours }(\mathrm{mg} / \mathrm{kg})(\text { mean } \pm \mathrm{SD})\end{array}$ & $\begin{array}{c}\text { Total dose over first } 24 \\
\text { hours }(\mathrm{mg} / \mathrm{kg})(\text { mean } \pm \text { SD) }\end{array}$ \\
\hline Artemether ir*, single dose & $2.08(0.42-5)$ & $6.7 \pm 1.19$ & $6.7 \pm 1.19$ & $6.7 \pm 1.19$ \\
\hline Artemisinin ir, single dose & $19(4-4 I)$ & $20.0 \pm 0$ & $20.0 \pm 0$ & $20.0 \pm 0$ \\
\hline $\begin{array}{l}\text { Artemisinin ir, multiple } \\
\text { dose }\end{array}$ & $20(0.7-62)$ & $31.5 \pm 8$ & $45.1 \pm 14$ & $45.1 \pm 14$ \\
\hline $\begin{array}{l}\text { Artesunate ir, multiple } \\
\text { dose }\end{array}$ & $19(1.3-80)$ & $6.65 \pm 4$ & $8.1 \pm 4.17$ & $14.8 \pm 7.64$ \\
\hline $\begin{array}{l}\text { Artesunate ir, single dose - } \\
10 \mathrm{mg} / \mathrm{kg}\end{array}$ & $12(1.33-58)$ & $9.4 \pm 2.47$ & $9.4 \pm 2.47$ & $9.4 \pm 2.53$ \\
\hline Artesunate per os & $6(0.92-15)$ & $4.0 \pm 0$ & $4.0 \pm 0$ & $4.0 \pm 0$ \\
\hline Artemisinins parenteral & $18(0.5-66)$ & $2.94 \pm 0.61$ & $2.94 \pm .0 .6$ & $3.43 \pm 0.99$ \\
\hline Quinine parenteral & $3(0.3-49)$ & $|7.6 \pm 4.3|$ & $24.2 \pm 4.96$ & $36.6 \pm 5.7$ \\
\hline $\begin{array}{l}\text { Quinine parenteral + } \\
\text { Artesunate ir }\end{array}$ & $45(32-60)$ & - & - & - \\
\hline $\begin{array}{l}\text { Artesunate ir, single }-20 \\
\mathrm{mg} / \mathrm{kg}\end{array}$ & $6.3(2-30)$ & $19.4 \pm 1.63$ & $19.4 \pm 1.63$ & $20.7 \pm 0.99$ \\
\hline
\end{tabular}

* ir: Intra-rectal

count was a significant covariate $(\mathrm{p} \leq 0.0001)$ in the Cox regression giving an adjusted $H R=0.52(p \leq 0.0001)$ for a single rectal treatment versus parenteral treatment.

\subsection{Response between different derivatives given rectally} Multiple dose artesunate versus single dose artesunate

All multiple dose artesunate studies were undertaken in Asia and regression analyses were limited to patients from this region. The crude PRR at 12 hours with a multiple dose was $52.6 \%$ compared to a single dose of rectal artesunate at $64.1 \%$. In the adjusted model (Table 4 ), the PRR at 12 hours was $32.7 \%$ with multiple dose treatment and $57.7 \%$ with single dose therapy, with severity of disease a significant covariate $(\mathrm{OR}=19.5, \mathrm{p}=0.011)$.

At 24 hours, the mean PRR was $87.5 \%$ for the multiple dose treatment and $93.7 \%$ for the single dose. An adjusted logistic regression model indicated that a patient with moderately severe or severe disease had a five times greater chance of achieving a 90\% reduction of parasitaemia at 24 hours with single dose artesunate rectal treatment (multiple dose compared with single OR $=0.19$ ( $\mathrm{p}$ $\leq 0.0001)$ ), and that the total dose over 24 hours was the only variable independently influencing this outcome (Table 4). In all studies with multiple dose rectal administration with artesunate (all in Asia), a $200 \mathrm{mg}$ suppository was provided sequentially at intervals over 72 hours, resulting in a mean exposure of $7.9 \mathrm{mg} / \mathrm{kg}$ over 12 hours and $14.9 \mathrm{mg} / \mathrm{kg}$ over 24 hours. Single dose studies attempted to provide a dose as close to $10 \mathrm{mg} / \mathrm{kg}$ as possible at initiation of therapy; the mean dose was $8.5 \mathrm{mg} / \mathrm{kg}$ over 24 hours $(10.1 \mathrm{mg} / \mathrm{kg}$ in studies in Thailand).

The Kaplan-Meier analysis (log-rank test $\mathrm{p}=0.45$ ) and Cox regression adjusted analysis indicated no significant difference in the time to clearance of parasitaemia between multiple and single dose rectal artesunate treatment $(\mathrm{HR}=1.04 \mathrm{p}=0.76)$, the assumption of proportional hazards not being justified. However, parasitaemia at baseline $(\mathrm{HR}=0.99)$, total treatment dose prior to 12 hours $(\mathrm{HR}=1.1)$, and patient age $(\mathrm{HR}=0.64)$ were three significant covariates in this analysis (all at $\mathrm{p}=0.0001$ ).

\section{Single dose artemisinin versus single dose artesunate}

Two Vietnamese studies with single dose artemisinin given rectally over 24 hours were compared with single dose artesunate studies in Asia. Mean PRRs at 12 hours with single dose artemisinin and single dose artesunate suppositories were $72.3 \%$ and $64.2 \%$, respectively. Corresponding PRRs at 24 hours were 95.5\% and 93.9\%, respectively, with $\mathrm{OR}=1.13(\mathrm{p}=0.813)$. The Kaplan Meier analysis (log-rank test $\mathrm{p}=0.71$ ) and Cox regression analysis did not show a significant difference in time to parasite clearance between the two treatments $(H R=1.07$, $\mathrm{p}=0.73)$. The only covariate of significance was parasite count at initiation of treatment $(H R=0.99, p=0.023)$.

\section{Multiple dose artemisinin versus single dose artemisinin}

There were three studies in the comparison: one study with single dose artemisinin over 24 hours and two studies with multiple dose artemisinin, all conducted in Vietnam. Mean PRR at 12 hours was $72.3 \%$ with single dose artemisinin suppositories and $63.2 \%$ for multiple dose artemisinin. No covariate, including total dose which was significantly higher in the multiple dose group $(20 \mathrm{mg} / \mathrm{kg}$ versus $45 \mathrm{mg} / \mathrm{kg}, \mathrm{p} \leq 0.0001)$, influenced outcome in the adjusted model at 12 hours. At 24 hours, the crude mean values of PRR were $89.1 \%$ for multiple dose artemisinin treatment and $95.5 \%$ for single dose treatment with an $\mathrm{OR}=0.60 \mathrm{p}=0.40$. The Kaplan Meier survival analysis 


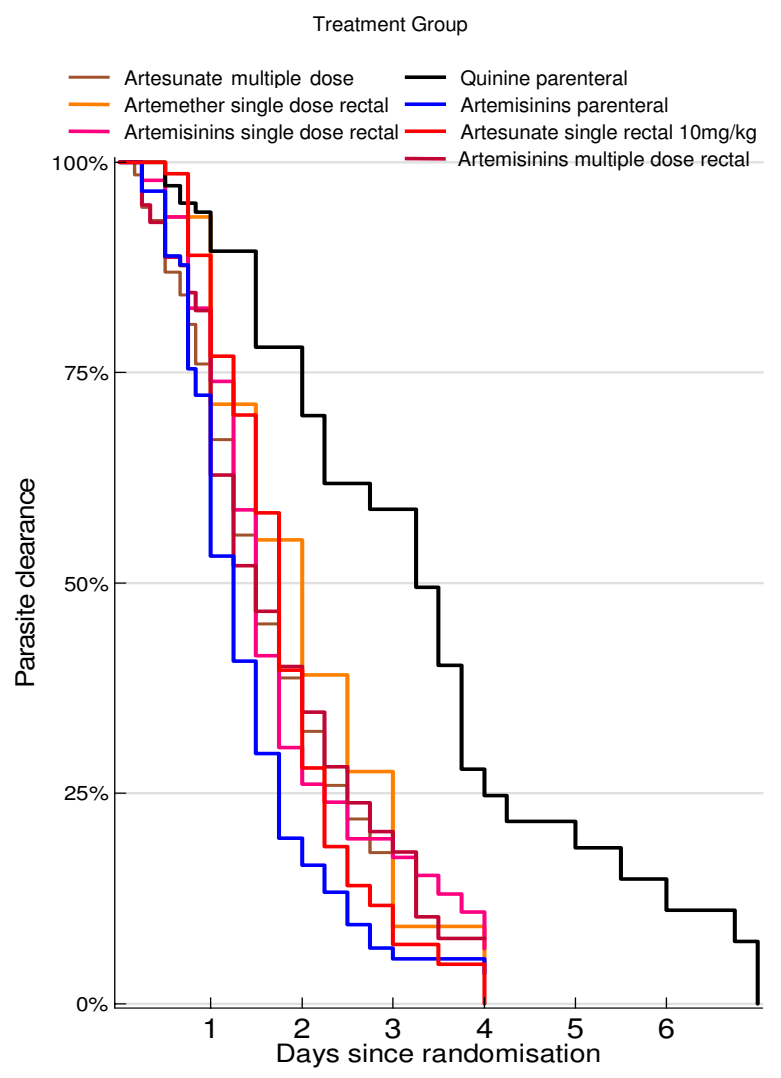

Figure I

Cumulative probability of having parasites: parenteral quinine versus treatment with artemisinins.

(log rank test $\mathrm{p}=0.98$ ) and the adjusted Cox regression analysis of multiple versus single $(\mathrm{HR}=1.24, \mathrm{p}=0.27)$ did not indicate any difference in time to parasite clearance between the two groups although parasite count at baseline was a significant covariate $(\mathrm{HR}=0.99, \mathrm{p}=0.05)$. Patient weight data was not available to enable estimation of the effect of dose $(\mathrm{mg} / \mathrm{kg})$.

\section{Single dose artemether versus single dose artesunate}

Only one study with artemether suppositories was performed (Uganda), with a single rectal dose of artemether being given once daily for 7 days. Mean PRR at 12 hours was $53.5 \%$ for single dose rectal artemether compared with $73.5 \%$ with single dose artesunate $(\mathrm{p} \leq 0.0001)$. No covariate influenced this outcome significantly. At 24 hours, mean PRR was $83.1 \%$ for single dose artemether and $96.7 \%$ with single dose artesunate ( $\mathrm{p} \leq 0.0001)$. The odds of achieving a $90 \%$ reduction in parasitaemia at 24 hours was about one fifth for artemether compared to artesunate $(\mathrm{OR}=0.22, \mathrm{p}=0.002$ ) in a moderately severe or severe patient. Mean total treatment dose during the initial 24 hours with single dose artemether was $6.72 \mathrm{mg} /$ $\mathrm{kg}$ compared with $9.4 \mathrm{mg} / \mathrm{kg}$ with single dose artesunate. The Kaplan Meier analysis (log-rank test $\mathrm{p}=0.18$ ) and Cox regression analysis ( $\mathrm{HR}=1.56, \mathrm{p}=0.21$ ) of time-toclearance of parasitaemia showed no significant differences between the two types of artemisinin-based suppositories: artemether given once daily for 7 days versus artesunate given only once in the first 24 hours and followed by sulphadoxine-pyrimethamine $(\mathrm{HR}=1.56, \mathrm{p}=$ $0.21)$.

\section{Effect of consolidation treatment on recrudescence}

Consolidation treatment varied (Table 5). A multiple Cox regression analysis of time-to-recrudescence gave a nonsignificant difference between an intra-rectal and parenteral artemisinin derivative when both were followed by mefloquine ( $\mathrm{HR}=0.78, \mathrm{p}=0.639$ ) but parasitaemia at 72 hours was a significant covariate in the analysis ( $\mathrm{HR}=0.99, \mathrm{p}=0.003$ ). However, in a comparison of intra-rectal treatment followed by sulphadoxinepyrimethamine (SP) versus intra-rectal treatment followed by mefloquine, the Kaplan Meier analysis (log-rank test $\mathrm{p} \leq 0.0001)$ and Cox regression analysis $(\mathrm{HR}=0.36, \mathrm{p}$ $=0.006$ ) of time to recrudescence between the two treatments showed a significant difference in favour of mefloquine, with parasitaemia at 72 hours ( $\mathrm{HR}=0.99, \mathrm{p}=$ $0.005)$ and region of study $(H R=0.16, p=0.001)$ being significant covariates in the analysis (Figure 3 ).

\section{Safety}

A total of 196 adverse events were reported in 140 $(17.8 \%)$ of the 786 patients treated with rectal artemisinins (Table 6). By comparison 67 adverse events were reported in $30(24.3 \%)$ of 123 patients treated with parenteral quinine.

Of the 196 adverse events in patients treated with suppositories, 37 events in 21 patients were considered to be potentially drug-related, based on classifications provided by the clinical investigators. A further 105 events in 69 patients were classified as non-drug related and 50 events in 54 patients could not be or were not assigned a cause. Therefore, overall, $2.7 \%(21 / 786)$ of all rectal artemisinintreated patients were thought to have had a potentially drug-related adverse event, $8.8 \%(69 / 786)$ a non-drug related adverse event and an additional 6.4\% (54/786) had an adverse event of uncertain causality. By comparison, 27 of 67 (40.3\%) reported adverse events occurring in 123 quinine-treated patients were considered drugrelated meaning that $22.0 \%(27 / 123)$ of quinine-treated patients experienced an adverse event that was considered potentially drug-related.

Approximately 29.7\% (11/37) of suspected drug-related adverse events in rectal artemisinin-treated patients were defined as affecting the body as a whole (including fever, 
Table 3: Parasite reduction ratio at 12 and 24 hours compared with quinine: mixed model results

\begin{tabular}{|c|c|c|c|c|c|c|c|c|}
\hline & \multicolumn{3}{|c|}{ I 2 hr final model } & \multicolumn{3}{|c|}{24 hr descriptive model ${ }^{* *}$} & \multicolumn{2}{|c|}{$24 \mathrm{hr}$ final model } \\
\hline & $\%$ & p-value & $\mathbf{N}$ & $\%$ & p-value & $\mathbf{N}$ & Odds Ratio & p-value \\
\hline \multicolumn{9}{|c|}{ Single dose Rectal Artemisinin vs Parenteral Quinine } \\
\hline Parenteral quinine & 48.6 & & 35 & 68.7 & & 30 & & \\
\hline Rectal artemisinin & 72.3 & 0.337 & 46 & 95.5 & 0.29 & 46 & $8.2^{*}$ & 0.000 \\
\hline \multicolumn{9}{|c|}{ Multiple dose Rectal Artesunate vs Parenteral Quinine } \\
\hline Parenteral Quinine & 27.5 & & 123 & 67.1 & & 106 & & \\
\hline Multiple rectal artesunate & 56.5 & 0.04 & 272 & 89 & 0.004 & 254 & 11.03 & 0.009 \\
\hline \multicolumn{9}{|c|}{ Multiple Rectal Artemisinin vs Parenteral Quinine } \\
\hline Parenteral Quinine & 48.6 & & 35 & 68.7 & & 30 & & \\
\hline Multiple rectal artemisinin & 63.3 & 0.343 & 98 & 89.1 & 0.090 & 80 & $3.70^{*}$ & 0.004 \\
\hline \multicolumn{9}{|c|}{ Single dose Rectal Artesunate vs Parenteral Quinine } \\
\hline Parenteral & 36 & & 293 & 63.7 & & 106 & & \\
\hline Rectal & 79 & 0.000 & 123 & 99 & 0.000 & 264 & 23.5 & 0.000 \\
\hline Age $5-14$ yrs*** & -12 & 0.043 & & -9.4 & 0.015 & & 0.33 & 0.015 \\
\hline Age $>14$ yrs*** & -18 & 0.026 & & -6.9 & 0.152 & & 0.32 & 0.021 \\
\hline Severe disease & & & & 11.5 & 0.045 & & & \\
\hline
\end{tabular}

\footnotetext{
* No solution was found for the mixed model. Corresponding non-hierarchical regression used instead.

** Descriptive estimates of parasite reductions at 24 hours are provided only for comparisons with 12 hour estimates, see section 'Statistical analysis'

**** Reference category is $<5$ years
}

headache and unspecified pain), 2.7\% (1/37) were related to the nervous system (dizziness), $8.1 \%$ (3/37) were related to the special senses (hearing impairment) and $48.6 \%(18 / 37)$ related to the gastrointestinal system (vomiting, nausea, diarrhoea, constipation, abdominal pain). For those in the quinine comparator group, 25.9\% (7/27) of adverse events were related to the nervous system, $29.6 \%(8 / 27)$ to the digestive system, $18.5 \%(5 / 27)$ affected special senses/hearing and $14.8 \%(4 / 27)$ the haemopoetic system. A meaningful comparison of safety pro- files between the different artemisinin products was beyond the scope of this analysis. It should be noted that most of the safety data presented here are from patients treated with either artesunate (591) or artemisinin suppositories (144).

In summary, the total incidence of adverse events considered by clinicians to be possibly drug-related was estimated at being between $2.7 \%$ and $9.0 \%$ of all rectal artemisinin-treated patients, compared with $22 \%$ of qui-

Table 4: Parasite reduction ratio at 12 and 24 hours: Mixed model results

\begin{tabular}{|c|c|c|c|c|c|c|c|c|c|}
\hline & \multicolumn{3}{|c|}{ I 2 hr final model } & \multicolumn{3}{|c|}{24 hour descriptive model** } & \multicolumn{3}{|c|}{$24 \mathrm{hr}$ final model } \\
\hline & $\%$ & p-value & $\mathbf{N}$ & $\%$ & p-value & $\mathbf{N}$ & Odds Ratio & p-value & $\mathbf{N}$ \\
\hline \multicolumn{10}{|c|}{ Single Rectal Artemisinin or Artesunate vs Parenteral Artemisinins } \\
\hline Parenteral & 45.7 & & 225 & 83.8 & & 49 & & & 179 \\
\hline Rectal & 59.1 & 0.018 & 339 & 90.0 & 0.069 & 331 & $1.75^{*}$ & 0.072 & 201 \\
\hline Severe malaria & 16.6 & 0.008 & & & & & & & \\
\hline \multicolumn{10}{|c|}{ Multiple Artesunate vs Single Artesunate } \\
\hline Single artesunate & 57.7 & & 169 & 93.7 & & 80 & & & 155 \\
\hline Multiple artesunate & 32.7 & 0.001 & 249 & 87.5 & 0.279 & 307 & 0.19 & 0.004 & 232 \\
\hline Total dose at 24 hours & 19.5 & 0.011 & & & & & 1.14 & 0.008 & \\
\hline \multicolumn{10}{|c|}{ Single Artemisinin vs Single Artesunate } \\
\hline Single artesunate & $64.2^{*}$ & & 169 & 93.9 & & 46 & & & 46 \\
\hline Single artemisinin & 72.3 & 0.262 & 46 & 95.5 & 0.792 & 155 & $1.13^{*}$ & 0.813 & 155 \\
\hline \multicolumn{10}{|c|}{ Multiple Artemisinin vs Single Artemisinin } \\
\hline Single artemisinin & 72.3 & & 46 & 95.5 & & 80 & & & 80 \\
\hline Multiple artemisinin & 63.2 & 0.545 & 98 & 89.1 & 0.348 & 46 & $0.60 *$ & 0.403 & 46 \\
\hline \multicolumn{10}{|c|}{ Single Artemether vs Single Artesunate } \\
\hline Single artesunate & 73.5 & & 51 & 96.7 & & 109 & & & 109 \\
\hline Single artemether & 53.5 & 0.000 & 124 & 83.1 & 0.000 & 41 & $0.22 *$ & 0.002 & 41 \\
\hline
\end{tabular}

* No solution was found for the mixed model. Corresponding non-hierarchical regression used instead.

** Descriptive estimates of parasite reductions at 24 hours are provided only for comparisons with 12 hour estimates, see section 'Statistical analysis' 


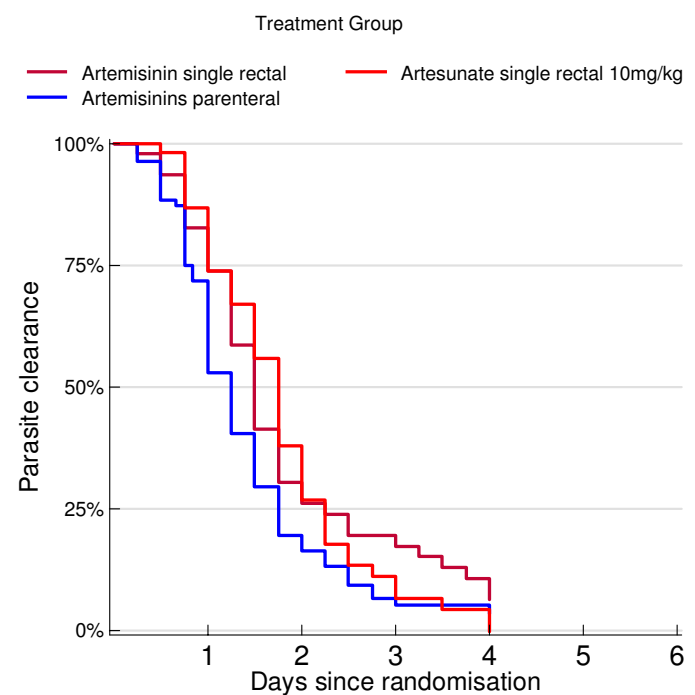

\section{Figure 2}

Cumulative probability of having parasites: parenteral artemisinins versus rectal artemisinins.

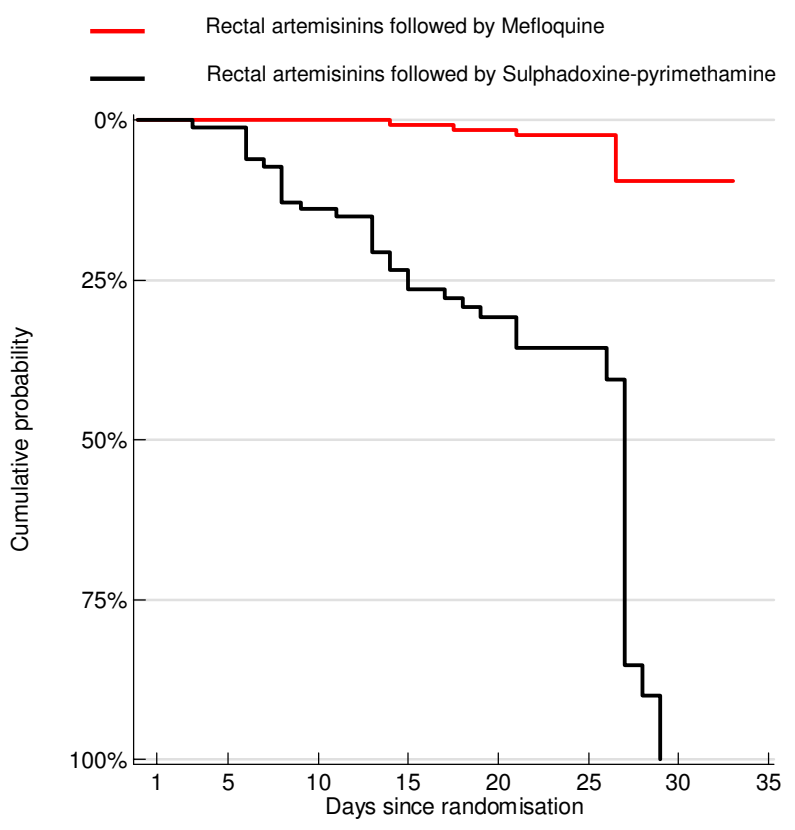

Figure 3

Cumulative probability of recrudescing with consolidation treatment. nine-treated patients. The majority of possibly drugrelated adverse events in rectal artemisinin-treated patients involved either the gastrointestinal system or were generalized and non-specific in nature and were not severe.

\section{Discussion}

This review addresses the lack of any data directly comparing the therapeutic efficacy and safety of the different rectal preparations of artemisinin derivatives. The pooled analysis of individual patient data suggest that artemisinin and artesunate suppositories rapidly eliminate parasites and are safe. There is far less evidence for artemether [32] and no studies of dihydroartemisinin suppositories were available to be included in this analysis. The results indicate that both artemisinin and artesunate, whether as single or multiple dose regimens, induce a superior parasitological response than parenteral quinine over the 24 hours following initiation of treatment. Regimens employing a higher single dose of rectal artesunate were five times as likely to result in $>90 \%$ parasite reductions at 24 hours than were multiple lower doses of rectal artesunate or than a single administration of artemether. These results imply that dosage regimens that result in immediate high blood concentrations of drug $[10,30,34,38]$ are those best able to reduce parasitaemia in patients with evolving severe malaria and that sustained drug exposure achieved by sequential treatment with moderate doses $[20,21,35,39]$ offers no therapeutic advantage.

The analysis used the rate of parasite clearance in the first 24 hours following treatment as the primary endpoint to compare therapeutic efficacy of alternative drugs and regimens. This endpoint has been commonly used in studies of antimalarial efficacy, particularly for treatments intended for severe malaria [40]. Parasite clearance is a surrogate marker of clinical response but it cannot be assumed that superior parasite clearance equates with improved clinical outcome and lower mortality. Although parenteral artemisinin derivatives have long been recognised as having superior parasite clearance to quinine, it remained uncertain until recently whether this characteristic converted into a survival benefit. A recent trial comparing iv artesunate with parenteral quinine demonstrated a $30 \%$ lower mortality with artesunate, confirming that more rapid initial parasite clearance may translate to reduced mortality in severe adult malaria [41]. Therefore, although the current pooled analysis was not powered to assess mortality as an endpoint, the differences in parasite clearance rates between rectal artemisinins and parenteral quinine, and between different rectal artemisinin dosing regimens, should be regarded as important indicators of possible real differences in therapeutic efficacy and clinical benefit. It should also be noted that any future study designed to use mortality as an end- 
Table 5: Consolidation treatment used in different clinical studies

\begin{tabular}{|c|c|c|c|c|}
\hline Initial Treatment group & Consolidation Treatment & Follow-up period & $\begin{array}{l}\text { Study Identification/Year of } \\
\text { Enrolment (Ref) }\end{array}$ & Total patients \\
\hline Artemether ir*, single dose & Artemether ir & 7 days & Aceng 2002-3 [32] & 51 \\
\hline Artemisinin ir, single dose & Mefloquine + SP & 72 hours & Hien 1998 & 46 \\
\hline \multirow{2}{*}{ Artemisinin ir, multiple dose } & Mefloquine & None post discharge & Phuong |992-5 [31] & 46 \\
\hline & & & Vinh 1992-4 [33] & 52 \\
\hline \multirow[t]{5}{*}{ Artesunate ir, multiple dose } & Artesunate + SP & 72 hours & Karunajeewa 2003-4 [34] & $4 I$ \\
\hline & Mefloquine & 28 days & Looareesuwan 1995 [35] & 60 \\
\hline & & & Than 1998 & 100 \\
\hline & & None post discharge & Bhatt 1994-5 [36] & 23 \\
\hline & Chloroquine or SP & None post discharge & Karunajeewa 200I [37] & 48 \\
\hline \multirow[t]{6}{*}{ Artesunate ir, single dose } & Artesunate + Mefloquine & $28-42$ days & Van Vugt 1997-9 & 44 \\
\hline & & 28 days & Looareesuwan 2000 & 69 \\
\hline & Mefloquine & 28 days & Looareesuwan 1996 & 26 \\
\hline & Chloroquine or SP & 30 days & Krishna $1996[10]$ & 23 \\
\hline & SP & $28-42$ days & Molyneux 1997-8 [30] & 113 \\
\hline & Mefloquine-SP & 72 hours & Hien 1998 & 44 \\
\hline Artesunate per os & Artesunate + Mefloquine & $28-42$ days & Van Vugt 1997-9 & 17 \\
\hline \multirow[t]{5}{*}{ Artemisinins parenteral } & Artesunate $+\mathrm{SP}$ & 72 hours & Karunajeewa 2003-4 [34] & 38 \\
\hline & Mefloquine & 28 days & Looareesuwan 1996 & 24 \\
\hline & & None post discharge & Phuong 1992-5 [31] & 40 \\
\hline & & & Vinh 1992-4 [33] & 123 \\
\hline & Chloroquine or SP & 30 days & Krishna $1996[10]$ & 11 \\
\hline \multirow[t]{3}{*}{ Quinine parenteral } & Quinine & 7 days & Aceng $2002-3$ [32] & 52 \\
\hline & SP & $28-42$ days & Barnes $1998[30]$ & 36 \\
\hline & & None post discharge & Phuong 1992-5 [31] & 35 \\
\hline Quinine parenteral + Artesunate ir & SP & 42 days & Barnes $1998[30]$ & 5 \\
\hline Grand Total & & & & 1167 \\
\hline
\end{tabular}

*ir: Intra-rectal

point to compare different rectal artemisinins (or to demonstrate non-inferiority of a rectal artemisinin with a parenteral preparation such as iv artesunate) would require such a large sample size that it is unlikely ever to be implemented. Therefore the surrogate marker of parasite clearance used in this analysis is likely to remain the best available evidence on which to base comparisons of treatment efficacy for the rectal artemisinins.

Table 6: Adverse events noted in patients treated with suppositories and parenteral treatment, by treatment group.

\begin{tabular}{|c|c|c|c|c|}
\hline & Rectal artemisinin & $\begin{array}{l}\text { Non-rectal artemisinin } \\
\text { comparator }\end{array}$ & $\begin{array}{c}\text { Non-artemisinin comparator } \\
\text { (quinine) }\end{array}$ & TOTAL \\
\hline Total no. patients included in analysis & 786 & 253 & 123 & 1162 \\
\hline $\begin{array}{l}\text { Total no. (\%) of patients in whom one or } \\
\text { more adverse event reported }\end{array}$ & $140(18)$ & $24(9)$ & $30(24)$ & 194 \\
\hline Total no. of adverse events: & 196 & 43 & 67 & 306 \\
\hline \multicolumn{5}{|l|}{ Classification (aetiology): } \\
\hline Possibly drug-related & 37 & 14 & 27 & 78 \\
\hline Not likely to be drug related & 105 & 28 & 40 & 173 \\
\hline Unable to be classified & 54 & 1 & 0 & 55 \\
\hline \multicolumn{5}{|l|}{$\begin{array}{l}\text { Classification of possibly drug-related } \\
\text { events according to body system: }\end{array}$} \\
\hline Generalised & 11 & I & 0 & 12 \\
\hline Neurological & 1 & 1 & 7 & 9 \\
\hline Digestive & 18 & 10 & 8 & 36 \\
\hline Urogenital & 1 & 1 & 0 & 2 \\
\hline Haemopoetic & 3 & I & 4 & 8 \\
\hline Special senses (hearing) & 3 & 0 & 5 & 8 \\
\hline Other & 0 & 0 & 3 & 3 \\
\hline
\end{tabular}


There has been a recent systematic review of published data on rectal artemisinin derivatives with a focus on pharmacokinetics of various preparations and a summary of efficacy[42]; however there were less data and limited capacity to standardize definitions and account for statistical heterogeneity. In contrast, the current meta-analysis synthesizes individual patient data from studies meeting well-defined inclusion criteria and for whom standardized end-points were calculated. The analysis has enabled a robust and statistically powerful comparison of efficacy outcomes between rectal artemisinins, parenterally administered artemisinins and parenteral quinine that has had the capacity to examine and allow for the influence of covariates such as age, geographic origin and disease severity. Given that only a small number of direct comparative trials have been performed, this meta-analysis of 1162 individual patients represents a significant contribution to the available comparative efficacy data on rectal artemisinins. In particular, its results showing that early parasite clearance of rectal artemisinins is clearly superior to that of quinine, and appears equivalent to that of parenteral artemisinins is an important observation, given the results of the recent SEQUAMAT trial[41].

There are methodological limitations inherent in making comparisons of safety across several trials and in attributing causality to adverse events in patients with malaria. Overall the data suggest that the artemisinin based suppositories studied have a benign safety profile, consistent with that of the artemisinins in general[43,44]. There were no special concerns related specifically to the rectal route of administration and there were no reports suggestive of serious neurotoxicity. Neurotoxicity of the artemisinin derivatives has been described in animals but this now appears to be associated with sustained exposure to the central nervous system rather than peak levels [45]. Therefore a single dose as pre-referral treatment (rather than multiple dosing) may also have additional theoretical benefits in terms of safety as well as efficacy. Pharmacokinetic data have largely been derived from studies of artesunate $[10,20,21,30,31,38,47]$ and artemisinin[14$18,48,49]$ with little data on rectal formulations of artemether[32] or dihydroartemisinin[22]. In the absence of sufficient pharmacokinetic information it cannot be assumed that all rectal preparations have the same efficacy or safety profile. Well-designed clinical trials that directly compare the efficacy, safety and pharmacokinetic profile of the different suppository formulations are needed.

The evidence from this analysis supports the WHO recommendation for the use of artesunate and artemisinin as initial pre-referral treatment[8]. The analysis was not designed to assess long-term cure rates and there are insufficient data on which to substantiate the use of rectal treatment for full management of severe malaria.

\section{Conclusion}

Early effective treatment with artemisinin based suppositories has potential as a lifesaving intervention, particularly at the periphery of the health-care system, where suppositories might be administered early in lieu of parenteral treatment in remote communities by relatively untrained personnel. Combined with accurate diagnosis and artemisinin combination therapy, rectal artemisinins have been effectively used to reduce malaria incidence and mortality in Asia $[3,50,51]$, an approach which holds great promise for malaria control elsewhere.

\section{Competing interests}

Dr Karunajeewa has received funding for investigatordriven research from Mepha pharmaceuticals, AeschBasel, Switzerland, manufacturers of artesunate suppositories and has received honoraria for writing technical reports for the same company. No other authors have a conflict of interest.

\section{Authors' contributions}

The authors accept full responsibility for the overall content of this report. MG and MW are staff members of the World Health Organization. IR and MW established and executed the search strategy. MG contacted the authors of published and unpublished material for individual patient data; IR and MP extracted the efficacy data and MW and MG extracted and analysed the safety data with HK. MP led the statistical analysis of efficacy conducted and interpreted by IR and MG. MW, HK and MG conducted the safety analysis. All authors reviewed and interpreted the results and analyses. MG wrote the first draft, reviewed and finalized by all authors. All authors read and approved the final manuscript. The authors alone are responsible for the views expressed in this publication and they do not necessarily represent the decisions, policy or views of the World Health Organization.

\section{Acknowledgements}

The authors are grateful to all the investigators who provided the data for the analysis: Dr C. Phuong, Dr D. Bethell and the Dong Nai Pediatric Centre, Dong Nai, Vietnam; Harin Karunajeewa represents a collaborative research group comprising the University of Western Australia (Timothy Davis, Ken llett, Harin Karunajeewa) and the Papua New Guinea Institute of Medical Research (Peter Siba, Ivo Mueller); Prof T.Hien, Dr Vinh and staff at the Centre for Tropical Diseases, Cho Quan Hospital, Ho Chi Minh City, Vietnam for data on artemisinin suppositories and parenteral artemisinins; Prof S. Krishna and colleagues at the Komfo-Anoyke Teaching Hospital, Kumasi Ghana, Prof S. Looareesuwan and colleagues at the Faculty of Tropical Medicine, Mahidol University, Thailand, Prof Marlar Than and colleagues at the Department of Medicine, Malaria Clinical Research Unit of Department of Medical Research, Myanmar, Prof K. Barnes, University of Cape Town, South Africa, Prof M. Molyneux, Dept. of Paediatrics, College of Medicine, University of Malawi, Malawi, Dr Bhatt and colleagues at the Department of Medicine, Nairobi Kenya, Dr Michèle Van Vugt and colleagues at the Shoklo Malaria Research Unit, Mae Sot, Thailand for data on artesunate suppositories; and Dr J. Aceng, Prof J Tumwine and colleagues 
at Mulago Hospital, Kampala, Uganda, for data on artemether suppositories.

\section{References}

I. Li GQ, Guo XB, Jian HX, Fu LC, Shen LC, Li RS, Dai BQ, Li ZL: Observation on the efficacy of qinghaosu suppository in $\mathbf{1 0 0}$ cases of falciparum malaria. J Tradit Chin Med I985, 5: I59-I6I.

2. Hien TT, White NJ: Qinghaosu. Lancet 1993, 341:603-608.

3. Hien TT: An overview of the clinical use of artemisinin and its derivatives in the treatment of falciparum malaria in Viet Nam. Trans R Soc Trop Med Hyg 1994, 88:S7-S8.

4. Ribeiro IR, Olliaro P: Safety of artemisinin and its derivatives. A systematic review of published and unpublished clinical trials. Med Trop (Mars) 1998, 58:50-53.

5. Mclntosh HM, Olliaro P: Treatment of severe malaria with artemisinin derivatives. A systematic review of randomised controlled trials. Med Trop (Mars) 1998, 58:6I-62

6. Mclntosh HM, Olliaro P: Treatment of uncomplicated malaria with artemisinin derivatives. A systematic review of randomised controlled trials. Med Trop (Mars) 1998, 58:57-58.

7. Bar-Zeev N, White N: Evidence behind the WHO Guidelines: Hospital Care for Children: Efficacy and Safety of Artemisinin Derivatives in Children with Malaria. Journal of Tropical Pediatrics 2006, 52:78-82.

8. World Health Organization: WHO Guidelines for the Treatment of Malaria, 2006 edn World Health Organization; 2006.

9. White NJ: Clinical pharmacokinetics and pharmacodynamics of artemisinin and derivatives. Trans R Soc Trop Med Hyg 1994, 88(Suppl I):S4I-S43.

10. Krishna S, Planche T, Agbenyega T, Woodrow C, Agranoff D, BeduAddo G, Owusu-Ofori A, Appiah J, Ramanathan S, Mansor S, Navaratnam $\vee$ : Bioavailability and preliminary clinical efficacy of intrarectal artesunate in Ghanaian children with moderate malaria. Antimicrob Agents Chemother 200I, 45:509-5I6.

II. Teja-Isavatharm P, Nosten F, Kyle DE, Luxemburger C, ter Kuile FO, Peggins JO, Brewer TG, White NJ: Comparative bioavailability of oral, rectal, and intramuscular artemether in healthy subjects: use of simultaneous measurement by high performance liquid chromatography and bioassay. $\mathrm{Br} J$ Clin Pharmacol 1996, 42:599-604.

12. Bethell DB, Teja-Isavadharm P, Cao XTP, Pham TTT, Ta Thi TM, Tran Thi NT, Nguyen TTH, Pham TP, Kyle D, Day NP, White NJ: Pharmacokinetics of oral artesunate in children with moderately severe Plasmodium falciparum malaria. Trans $R$ Soc Trop Med Hyg 1997, 91:195-198.

13. Kyle DE, Teja-Isavadharm P, Li Q, Leo K: Pharmacokinetics and pharmacodynamics of qinghaosu derivatives: how do they impact on the choice of drug and the dosage regimens? Med Trop (Mars) 1998, 58:38-44.

14. Koopmans R, Dao DD, Kager PA, Nguyen XK, Tran KD, de Vries PJ, van Boxtel C): The pharmacokinetics of artemisinin suppositories in Vietnamese patients with malaria. Trans $R$ Soc Trop Med Hyg 1998, 92:432-436.

15. Koopmans RP, Le Dang H, Dao DD, Tran KD, Kager PA, Nguyen XK, van Boxtel CJ, de Vries PJ: The pharmacokinetics of artemisinin after administration of two different suppositories to healthy Vietnamese subjects. Am J Trop Med Hyg 1999, 60:244-247.

16. Titulaer HA, Zuidema J, Kager PA, Wetsteyn JC, Lugt CB, Merkus FW: The pharmacokinetics of artemisinin after oral, intramuscular and rectal administration to volunteers. J Pharm Pharmacol 1990, 42:810-813.

17. Ashton M, Nguyen DS, Nguyen VH, Gordi T, Trinh NH, Dinh XH, Nguyen TN, Le Dinh C: Artemisinin kinetics and dynamics during oral and rectal treatment of uncomplicated malaria. Clin Pharmacol Ther 1998, 63:482-493.

18. Duc DD, de Vries PJ, Nguyen XK, Le Nguyen B, Kager PA, van Boxtel C): The pharmacokinetics of a single dose of artemisinin in healthy Vietnamese subjects. Am J Trop Med Hyg 1994, 5 I:785-790.

19. DerSimonian R, Laird N: Meta-analysis in clinical trials. Control Clin Trials 1986, 7:177-188.

20. Benakis A, Binh TQ, Keundjian A, Scheiwe MW: Pharmacokinetics/Pharmacodynamics findings after repeated administration of ARTESUNATE thermostable suppositories
(RECTOCAPS) in Vietnamese patients with uncomplicated malaria. Eur J Drug Metab Pharmacokinet 2006, 3 I :4 I-45.

21. Halpaap B, Ndjave M, Paris M, Benakis A, Kremsner PG: Plasma levels of artesunate and dihidroartemisinin in children with plasmodium falciparum malaria in Gabon, after administration of $\mathbf{5 0} \mathbf{~ m g}$ artesunate suppositories. [Abstract]. Annual Congress of the Swiss Society of Tropical Medicine and Parasitology 1996.

22. llett KF, Batty KT, Powell SM, Binh TQ, Thu le TA, Phuong HL, Hung NC, Davis TM: The pharmacokinetic properties of intramuscular artesunate and rectal dihydroartemisinin in uncomplicated falciparum malaria. British Journal of Clinical Pharmacology 2002, 53:23-30.

23. Gomez-Landires EA: Efficacy of artesunate suppository followed by oral mefloquine in the treatment of severe falciparum malaria in endemic areas where resistance to chloroquine exists in Ecuador. Jpn J Trop Med Hyg 1996, 24:17-24.

24. Sabchareon A, Attanath $P$, Chanthavanich $P$, Phanuaksook P, Prarinyanupharb V, Poonpanich Y, Mookmanee D, Teja-Isavadharm P, Heppner DG, Brewer TG, Chongsuphajaisiddhi T: Comparative clinical trial of artesunate suppositories and oral artesunate in combination with mefloquine in the treatment of children with acute falciparum malaria. Am J Trop Med Hyg 1998 , 58: $11-16$

25. Tran TH, Arnold K, Nguyen TH, Pham PL, Nguyen TD, Bui MC, Le MT, Mach OP, Le HV, Pham PM: Single dose artemisinin-mefloquine treatment for acute uncomplicated falciparum malaria. Trans R Soc Trop Med Hyg 1994, 88:688-69l.

26. Gomez L, Jurado $M H$, Cambon $N$ : Randomised efficacy and safety study of two 3-day artesunate rectal capsule/mefloquine regimens versus artesunate alone for uncomplicated malaria in Ecuadorian children. Acta Tropica 2003, 89:47-53.

27. Awad M, Alkadru A, Behrens RH, Baraka OZ, EITayab IB: Descriptive study on the efficacy and safety of artesunate suppository in combination with other antimalarials in the treatment of severe malaria in Sudan. Am J Trop Med Hyg 2003, 68: $153-158$.

28. Pengsaa K, Sirvichayakul C, Na-Bangchang K, Thaiarporn I, Chaivisuth A, Wongsuwan A, Attanath P, Pojjaroen-Anant C, Wisetsing P, Chanthavanich $P$, Sabchareon A: Life-saving rectal artesunate for complicated malaria in children. Southeast Asian J Trop Med Pub Health 2005, 36:597-60I.

29. Birku Y, Makonnen E, Bjorkman A: Comparison of rectal artemisinin with intravenous quinine in the treatment of severe malaria in Ethiopia. East Afr Med J 1999, 76:154-159.

30. Barnes KI, Mwenechanya J, Tembo M, Mcllleron H, Folb PI, Ribeiro IR, Little F, Gomes M, Molyneux ME: Efficacy of rectal artesunate in the initial treatment of moderately severe malaria in African children and adults. Lancet 2004, 363:I598-I605.

31. Phuong XT, Bethell DB, Pham TP, Ta TT, Tran TN, Nguyen TT, Pham TT, Nguyen TT, Day NP, White NJ: Comparison of artemisinin suppositories, intramuscular artesunate and intravenous quinine for the treatment of severe childhood malaria. Trans $R$ Soc Trop Med Hyg 1997, 91:335-342.

32. Aceng JR, Byarugaba JS, Tumwine JK: Rectal artemether versus intravenous quinine for the treatment of cerebral malaria in children in Uganda: randomised clinical trial. BMJ 2005, 330:334.

33. Vinh H, Nguyen NH, Tran TB, Bui MC, Nguyen HP, Tran TH, Phan TQ, Arnold K, Tran TH: Severe and complicated malaria treated with artemisinin, artesunate or artemether in Viet Nam. Trans R Soc Trop Med Hyg 1997, 91:465-467.

34. Karunajeewa HA, Reeder J, Lorry K, Dabod E, Hamzah J, Page-Sharp M, Chiswell GM, llett KF, Davis TM: Artesunate suppositories versus intramuscular artemether for treatment of severe malaria in children in Papua New Guinea. Antimicrob Agents Chemother 2006, 50:968-974.

35. Looareesuwan S, Wilairatana P, Molunto W, Chalermrut K, Olliaro P, Andrial M: A comparative clinical trial of sequential treatments of severe malaria with artesunate suppository followed by mefloquine in Thailand. Am J Trop Med Hyg 1997, 57:348-353.

36. Bhatt KM, Bhatt SM, Omonge E, Oteko L, Andrial M: Efficacy and tolerability of a sequential artesunate suppository-mefloquine treatment of severe falciparum malaria. Jpn J Trop Med Hyg 1996, 24:59-63. 
37. Karunajeewa HA, Kemiki A, Alpers MP, Lorry K, Batty KT, llett KF, Davis TM: Safety and therapeutic efficacy of artesunate suppositories for treatment of malaria in children in Papua New Guinea. Pediatr Infect Dis 2003, 22:25I-256.

38. Simpson JA, Agbenyega T, Barnes KI, di Perri GD, Folb P, Gomes M, Krishna S, Krudsood S, Looareesuwan S, Mansor S, Mcllleron $\mathrm{H}$, Miller R, Molyneux M, Mwenechanya J, Navaratnam V, Nosten F, Olliaro P, Pang L, Ribeiro I, Tembo M, van Vugt M, Ward S, Weerasooriya K, Win K, White N]: Population pharmacokinetics of artesunate and dihydroartemisinin following intra-rectal dosing of artesunate in malaria patients. PLoS Medicine 2006, 3:e444.

39. Looareesuwan S, Wilairatana P, Vanijanonta S, Viravan C, Andrial M: Efficacy and tolerability of a sequential, artesunate suppository plus mefloquine, treatment of severe falciparum malaria. Ann Trop Med Parasitol 1995, 89:469-475.

40. White NJ: Assessment of the pharmacodynamic properties of antimalarial drugs in vivo. Antimicrob Agents Chemother 1997, 41:1413-1422.

41. South East Asian Quinine Artesunate Malaria Trial (SEAQUAMAT): Artesunate versus quinine for treatment of severe falciparum malaria: a randomised trial. The Lancet 2005, 366:717-725.

42. Karunajeewa HA, Manning L, Mueller I, llett KF, Davis TME: Rectal Administration of Artemisinin Derivatives for the Treatment of Malaria. JAMA: The Journal of the American Medical Association 2007, 297:238I-2390.

43. Price R, van Vugt M, Phaipun L, Luxemburger C, Simpson J, McGready R, ter Kuile F, Kham A, Chongsuphajaisiddhi T, White NJ, Nosten F: Adverse effects in patients with acute falciparum malaria treated with artemisinin derivatives. Am J Trop Med Hyg 1999, 60:547-555.

44. Taylor W, White NJ: Antimalarial Drug Toxicity: A Review. Drug Saf 2004, 27:25-6I.

45. Nontprasert A, Pukrittayakamee S, Prakongpan S, Supanaranond W, Looareesuwan S, White NJ: Assessment of the neurotoxicity of oral dihydroartemisinin in mice. Trans R Soc Trop Med Hyg 2002, 96:99-101.

46. Ittarat $\mathrm{W}$, Looareesuwan $\mathrm{S}$, Pootrakul $\mathrm{P}$, Sumpunsirikul $\mathrm{P}$, Vattanavibool P, Meshnick SR: Effects of alpha-thalassemia on pharmacokinetics of the antimalarial agent artesunate. Antimicrob Agents Chemother 1998, 42:2332-2335.

47. Karunajeewa HA, llett KF, Dufall K, Kemiki A, Bockarie M, Alpers MP, Barrett PH, Vicini P, Davis TME: Disposition of Artesunate and Dihydroartemisinin after Administration of Artesunate Suppositories in Children from Papua New Guinea with Uncomplicated Malaria. Antimicrob Agents Chemother 2004, 48:2966-2972.

48. Sidhu JS, Ashton M, Huong NV, Hai TN, Karlsson MO, Sy ND, Jonsson EN, Cong LD: Artemisinin population pharmacokinetics in children and adults with uncomplicated falciparum malaria. Br J Clin Pharmacol 1998, 45:347-354.

49. Dien TK, de Vries PJ, Nguyen XK, Koopmans R, Le Nguyen B, Dao DD, Kager PA, van Boxtel Cl: Effect of food intake on pharmacokinetics of oral artemisinin in healthy Vietnamese subjects. Antimicrob Agents Chemother 1997, 41:1069-1072.

50. Carrara V, Sirilak S, Thonglairuam J, Rojanawatsirivet C, Proux S, Gilbos V, Brockman A, Ashley EA, McGready R, Krudsood S, Leemingsawat S, Looareesuwan S, Singhasivanon P, White NJ, Nosten F: Deployment of Early Diagnosis and Mefloquine- Artesunate Treatment of Falciparum Malaria in Thailand: The Tak Malaria Initiative. PLoS Medicine 2006, 3: 183.

5I. Giao PT, Vries PJ, Binh TQ, Nam NV, Kager PA: Early diagnosis and treatment of uncomplicated malaria and patterns of health seeking in Vietnam. Trop Med Int Health 2005, I 0:919-925.

\section{Pre-publication history}

The pre-publication history for this paper can be accessed here:

http://www.biomedcentral.com/1471-2334/8/39/prepub
Publish with Biomed Central and every scientist can read your work free of charge

"BioMed Central will be the most significant development for disseminating the results of biomedical research in our lifetime. "

Sir Paul Nurse, Cancer Research UK

Your research papers will be:

- available free of charge to the entire biomedical community

- peer reviewed and published immediately upon acceptance

- cited in PubMed and archived on PubMed Central

- yours - you keep the copyright

Submit your manuscript here:

http://www.biomedcentral.com/info/publishing_adv.asp
BiolMedcentral 